\title{
Subject Screened for Study
}

National Cancer Institute

\section{Source}

National Cancer Institute. Subject Screened for Study. NCI Thesaurus. Code C70733.

An indication that an individual was screened for eligibility criteria to participate in a clinical study. 